\title{
The Application of the Traditional Architectural Modeling Art to Animation Scene Design
}

\author{
Shaohui LIU \\ Art Academy \\ Northeast Agricultural University \\ Harbin, Heilongjiang Province, China
}

\begin{abstract}
The traditional architectural modeling art as a precious treasure in traditional Chinese culture occupies a very important position in the world art kingdom, and it possesses incomparable artistic charm compared with other art forms. There are abundant contents in the traditional architectural modeling art. Under the changes of society, the traditional architectural modeling art is in unceasing development and enrichment, and it has become a symbol of the national culture. To get a sustainable development of Chinese animation, it is necessary to apply traditional Chinese elements to animation design. Only in this way, animation works can be of vitality. In this paper, the application of the traditional architectural modeling art to animation scene design is mainly analyzed.
\end{abstract}

Keywords- the traditional architectural modeling art; animation scene design; application

\section{INTRODUCTION}

In 1950s 1960s, the development of animation in China reached its peak, and the creators of animation works in many countries were inspired by traditional Chinese plastic art. In recent years, however, the traditional plastic art in China's original works begins to lose gradually, and Chinese original animation falls into a state of blind development. In the world pattern, Japanese animation and American animation have their own style and developing space. To get a sustainable development of Chinese animation, it is necessary to apply traditional Chinese elements to animation design. Only in this way, animation works can be of vitality. In the following, the application of the traditional architectural modeling art to animation scene design is mainly discussed in order to analyze the animation scene design methods as well as the matters needing attention.

\section{ANALYSIS ON THE POSTURE AND CHARACTERISTICS OF THE TRADITIONAL ARCHITECTURAL MODELING}

In the traditional Chinese architectural modeling, top priority is given to the wooden structure; the posture of the traditional architectural culture is a posture and style of the traditional culture. The traditional culture emerged on basis of the development of human history and culture. Traditional architecture has the characteristics of nationality and regionality. In different geographical environment, cultural background, and social structure, architectural culture is manifested differently, and this is also a profound reflection to the value orientation, design idea, and ethical ideas in each historical period. The characteristics of the traditional Chinese architectural modeling are mainly manifested in the following respects [1].

\section{A. The Group Layout Oriented at Courtyard Style}

In the traditional Chinese architectural modeling, the most significant characteristic was the group layout oriented at courtyard style. In this layout, "an architectural form was expressed using groups" was emphasized, and it was a product from the dynamic combination of the ancient patriarchal clan system with the traditional feudalism system and represented by dwelling houses, government offices, palaces, temples, etc. There were strict rules for the local parts of these buildings to follow; building groups were composed of different buildings and walls and centered on the fences, so that a closed courtyard pattern was constituted. Except some Buddhist buildings, the buildings oriented at courtyard style were layered one or two, and they were extended mainly to all directions in layout [2].

\section{B. The Wooden Frame Structure}

In the ancient Chinese traditional architecture, the wooden frame structure was the most commonly used as a building form. In the wooden frame structure, the connected stakes and wooden beams were emphasized to constitute the frame structure of the whole house, and this architectural structure was able to transfer the weights of roofs and eaves to stand columns. In the whole wooden frame structure, the mass of the buildings was unnecessarily burdened by the walls, and this was only used as a way to divide the space. Under this unique structure, buildings were not restricted by the wall bearing problem [3].

\section{The Diversified Modeling Structure}

The traditional Chinese architectural modeling features diversity and its representatives included religious buildings, military defense buildings, palace buildings, 
ritual sacrifice buildings, the structure of mausoleum, and civil residence and so on. In the traditional Chinese architecture, eaves were often supported with brackets, so that overhanging eaves of different forms such as flat, drooping, and upturned forms were constructed; they were able to effectively reflect the status and identity of the masters when they were applied to cabinet, floor, and platforms. In addition, slopes and curved surfaces were formed using different forms of roofs in the traditional Chinese architecture, and this architecture modeling was very rare all over the world.

\section{THE SIGNIFICANCE OF APPLYING THE TRADITIONAL ARCHITECTURAL MODELING ART TO ANIMATION SCENE} DESIGN

Ancient Chinese architecture was an important expression to Chinese national culture and the ancient Oriental culture, and it was rich in both spiritual and cultural connotations. The ancient building structure by relying on its forms and appearances was able to create a beautiful enjoyment for people, and its specific connotation is necessarily known well in animation scene design, so that the purpose of inheriting traditional Chinese culture and playing the role of carrying forward the traditional culture is achieved.

Under the changes of social economy, the incomes of people have rapidly increased. Under this background, the audiences of the animation scenes were significantly extended, and simultaneously the teenagers can enjoy the beautiful education in the animation, the middle-aged group can get the grief of mind in the animation, and the elderly can regain the memory of childhood in the animation. Animation is the most ideal carrier to transmit traditional culture; a variety of cultural forms such as the form of content, the form of arts, and the form of value orientation and music are contained in the animation. The traditional Chinese animation representatives Nezha Troubles in the Sea and Monkey King's fighting against the Heavenly Palace are taken as example [4]: in these two animation works, modeling, roles, colors, and scenes are rich in traditional Chinese modeling art, so that a unique national style emerges, and they produce a tremendous influence in China and foreign countries and become the representatives of Chinese animation works.

Under the development of animation industry, the competition has become fiercer and fiercer, so the nationalized industrial road is necessary to follow in order to realize development. Therefore, the close combination of animated scenes with the traditional Chinese architectural modeling art is necessary, and the traditional national culture should be applied in many aspects such as special effects, music, and art, so as to realize innovative development. This not only can help the world truly understand the traditional Chinese architectural modeling culture, and also can realize the sustainable development of China's animation industry.

\section{ANALYSIS ON THE APPLICATION OF THE TRADITIONAL ARCHITECTURAL MODELING ART TO ANIMATION SCENE DESIGN}

\section{A. The Application of the Traditional Cultural Characteristics to Animation Scene Construction}

Essentially, animation creation is a type of the traditional culture transmission and inheritance, and the task shouldered by animation scene design is significant. In order to realize the sustainable development of animation works, the traditional culture and art should be actively applied to animation scene design. It is necessary to note that building is a dynamic part of scene design. Building is a witness to both history and culture, and its essence lies in a replacement of human knowledge. In animation scene design, the relationship between time and space and the culture information can be well shown, and the application of the traditional architectural modeling art to animation scene design can play a role in manifesting the themes and reflecting the styles [5].

In any design work, the traditional culture plays a very important role, and there is no exception to animation design. As an important branch of the traditional culture, the traditional architectural modeling art can generate an important influence on animation scene design. In order to realize the development of Chinese cartoon works, it is necessary to get rid of imitations and plagiaries, actively apply the traditional plastic art, highlight the traditional Chinese national advantages, fully excavate the essence of the traditional culture, and apply the traditional architectural modeling art to animation scene design.

\section{B. Analysis on the Implications from the Traditional Architectural Culture for Animation Scene Design}

The main consumers of animation works are youth groups. Under the change of people's aesthetic concepts, people's demand for personalization has become more intense. Based on this factor, the personalized demand should be considered by animation design personnel in animation scene design, and then the scenes in China's animation design works are well distinguished with the works in other countries, so as to develop a personalized design style.

The traditional architectural modeling culture is an important part of traditional Chinese culture and owns unique characteristic, and it possesses incomparable artistic charm compared with other art forms. At present, China's animation works has also taken on a diversified development trend, in which the traditional architectural modeling art is applied to animation scene design for making animation works shine new vitality. In the animation works, scene is a visual language which is with no difference in the national boundaries and culture, because the people of different nationalities and different ages are the same to the visual language perception. Based on this factor, many designers have started to apply 
different types of architectural cultural elements to a lot of animation scene designs. Seen from the developing trend of the worldwide animation works, a profound analysis on the application of the traditional architectural modeling art and also its application to animation scene design work are of great significance.

\section{The Intersection with the Architectural Style of Each Period in Animation Scene Design}

Animation is a special space art, and animation scene design is necessary to closely combine with life. Animation scene is a virtual space, but also an art to reflect the real life. In terms of the macro-level, animation scene is made of both material space and social space, and it can reflect the relationship between time and space, living environment, and social environment in films, among which the most important is to reflect the relationship between time and space.

In particular social environment and living environment, building types will present a different characteristic. For example, small traditional architectural art is a space-time organic carrier. HUA Mulan, as animation works produced by Disney Company, is taken as an example: a large number of Chinese traditional elements such as the courtyards in the Ming and Qing dynasties are applied to the works, making the special characteristics of traditional Chinese culture effectively played; the scene design can effectively stimulate the readers' resonance, allowing them to better understand the traditional culture implied in the works [6].

\section{CONCLUSION}

The traditional architectural modeling art as a precious treasure in traditional Chinese culture occupies a very important position in the world art kingdom, and it possesses incomparable artistic charm compared with other art forms. There are abundant contents in the traditional architectural modeling art. Under the changes of society, the traditional architectural modeling art is in unceasing development and enrichment, and it has become a symbol of the national culture. With the application of the traditional architectural modeling art to animation scene design, the comprehensive competitiveness of China's animation works is effectively improved, and also the purpose of carrying forward the traditional culture is achieved.

\section{REFERENCES}

[1] Yali SHI. On the Application of Chinese Traditional Elements in Visual Communication Design [J]. Journal of Zhejiang Business Technology Institute, 2007 (03)

[2] Zhuoying LI, Yao ZHANG. The Combination of the Traditional Drama with the Modern Animation under the Intangible Protection-Sichuan Opera Animation Works The Autumn River for Example [J]. Sichuan Theatre, 2012 (02).

[3] Fengxia Qi, Yanmei ZHANG, Haixia QI, Ting ZHAO, Gang LI. The Application of Chinese Drama Elements to Cartoon Productions [J]. Journal of Hebei Normal University (Philosophy and Social Sciences Edition), 2011 (04).

[4] Fan ZHANG. Analysis on Chinese Traditional Culture Elements in the Theory of Interior Design [J]. Journal of Chifeng University (Social Sciences Edition), 2011(03).

[5] Mingzeng WANG. The Application of Chinese Traditional Culture Elements in the Modern Advertising Posters [J]. Science Education Newspaper (Education Scientific Research), 2011(17).

[6] Xiaoqun WU. The Application of the Micro traditional culture in modern graphic design [J]. The Young Writer, 2011(06). 